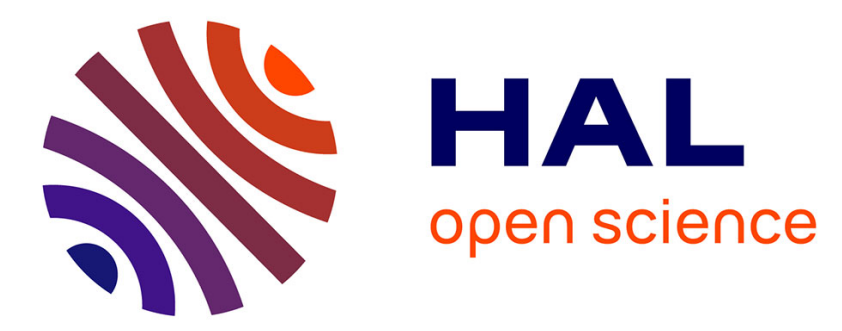

\title{
Camelina sativa Oil, Fatty Fish, and Lean Fish Do Not Markedly Affect Urinary Prostanoids in Subjects with Impaired Glucose Metabolism
}

\author{
Arja Erkkilä, Jetty C.-y. Lee, Maria Lankinen, Suvi Manninen, Ho Hang \\ Leung, Camille Oger, Vanessa de Mello, Ursula Schwab
}

\section{To cite this version:}

Arja Erkkilä, Jetty C.-y. Lee, Maria Lankinen, Suvi Manninen, Ho Hang Leung, et al.. Camelina sativa Oil, Fatty Fish, and Lean Fish Do Not Markedly Affect Urinary Prostanoids in Subjects with Impaired Glucose Metabolism. Lipids, 2019, 54 (8), pp.453-464. 10.1002/lipd.12176 . hal-02617294

\section{HAL Id: hal-02617294 \\ https://hal.science/hal-02617294}

Submitted on 3 Jun 2021

HAL is a multi-disciplinary open access archive for the deposit and dissemination of scientific research documents, whether they are published or not. The documents may come from teaching and research institutions in France or abroad, or from public or private research centers.
L'archive ouverte pluridisciplinaire HAL, est destinée au dépôt et à la diffusion de documents scientifiques de niveau recherche, publiés ou non, émanant des établissements d'enseignement et de recherche français ou étrangers, des laboratoires publics ou privés. 


\title{
Camelina sativa Oil, Fatty Fish, and Lean Fish Do Not Markedly Affect Urinary Prostanoids in Subjects with Impaired Glucose Metabolism
}

\author{
Arja T. Erkkilä ${ }^{1} \cdot$ Jetty C.-Y. Lee ${ }^{2} \cdot$ Maria Lankinen $^{1} \cdot$ Suvi Manninen $^{1} \cdot$ Ho Hang Leung $^{2}$ • \\ Camille Oger $^{3} \cdot$ Vanessa D. de Mello $^{1} \cdot$ Ursula S. Schwab $^{1,4}$
}

\begin{abstract}
Dietary fatty acids are suggested to affect oxidative stress; however, results from interventions have been inconclusive. The aim was to examine if fatty fish, lean fish, and Camelina sativa oil (CSO) affect the urinary prostanoid levels in subjects with impaired glucose metabolism. Altogether 79 participants aged 43-72 years completed a randomized controlled study lasting 12 weeks. There were four parallel groups, fatty fish, lean fish (four fish meals/week in both), CSO providing $10 \mathrm{~g} /$ day alphalinolenic acid (ALA), and control diet with limited fish and ALA containing oil consumption. Urinary prostanoids (prostaglandin $\quad \mathrm{F}_{2 \alpha}, \quad 5-\mathrm{F}_{2 \mathrm{t}^{-}}$-isoprostanes and $15-\mathrm{F}_{2 \mathrm{t}^{-}}$ isoprostane metabolites, isofuran, $8-\mathrm{F}_{3 \mathrm{t}}$-isoprostanes, and 4-(RS)-4- $\mathrm{F}_{4 \mathrm{t}}$-neuroprostane) of 72 participants (age: mean $( \pm \mathrm{SD}) \quad 58.9 \pm 6.5$ years; body mass index: $29.3 \pm 2.5 \mathrm{~kg} / \mathrm{m}^{2}$ ) collected over 12 -h were measured using liquid chromatography tandem-mass spectrometry. Plasma phospholipid fatty acids were determined using gas chromatography. Our study showed that the proportion of ALA in plasma phospholipids increased in the CSO group (overall difference among the groups $p$-value $<0.001)$. In the fatty fish group, proportions of
\end{abstract}

Arja T. Erkkilä

arja.erkkila@uef.fi

1 Institute of Public Health and Clinical Nutrition, University of Eastern Finland, Yliopistonranta, 70210 Kuopio, Finland

2 School of Biological Sciences, The University of Hong Kong, Pok Fu Lam Road, Hong Kong SAR

3 Institut des Biomolécules Max Mousseron, IBMM, Université de Montpellier, CNRS, ENSCM Faculté de Pharmacie, Av. Charles Flahault BP, 34093 Montpellier Cedex, France

4 Department of Medicine, Endocrinology and Clinical Nutrition, Kuopio University Hospital, Puijonlaaksontie, 70210 Kuopio, Finland eicosapentaenoic and docosahexaenoic acids increased (overall $p$-value $<0.001$ for both). Prostaglandin $\mathrm{F}_{2 \alpha}$ was higher in the CSO group than in the control group $(p<0.05)$, however, there were no other significant changes in urinary excretion of other prostanoids among the study groups. At baseline, arachidonic acid in plasma phospholipids was positively $(r=0.247, p<0.05)$ and ALA negatively $(r=-0.326, p<0.05)$ associated with urinary total isoprostanes. In conclusion, CSO, fatty fish, and lean fish consumption do not cause major changes in oxidative stress markers in subjects with impaired glucose tolerance.

Keywords Alpha-linolenic acid - Camelina sativa oil . Fish · Impaired glucose tolerance · Isoprostanes · Oxidative stress

$\begin{array}{lll}\text { Abbreviations } & \\ \text { ALA } & \text { alpha-linolenic acid } & \\ \text { ANCOVA } & \begin{array}{l}\text { analysis of covariance } \\ \text { body mass index }\end{array} & \\ \text { BMI } & \begin{array}{l}\text { Camelina sativa oil } \\ \text { docosahexaenoic acid }\end{array} & \\ \text { CSO } & \text { eicosapentaenoic acid } & \\ \text { DHA } & \text { electrospray ionization } & \\ \text { EPA } & \text { false discovery rate } & \\ \text { ESI } & \text { liquid chromatography-tandem } & \text { mass } \\ \text { FDR } & \text { spectrometry } & \\ \text { LC-MS/MS } & \text { multiple reaction monitoring } & \\ & \text { polychlorinated biphenyls } & \\ \text { MRM } & \text { prostaglandin } F_{2 \alpha} & \\ \text { PCB } & \text { polyunsaturated fatty acids } & \\ \text { PGF } & & \end{array}$




\section{Introduction}

Oxidative damage of lipids and its role in health and disease has been of interest for a long time. Isoprostanes were detected in the 1990s and they are suggested to be promising biomarkers for oxidative damage in human disease models (Morrow et al., 1990). Under oxidative stress, polyunsaturated fatty acids (PUFA) bound to phospholipids are autoxidized nonenzymatically and generate isoprostanes in situ. After hydrolysis by phospholipase $\mathrm{A}_{2}$, they can further metabolize to 2,3-dinor-15- $\mathrm{F}_{2 \mathrm{t}}$-isoprostane and 2,3-dinor5,6-dihydro- $15-\mathrm{F}_{2 \mathrm{t}}$-isoprostane and be excreted in the urine.

Several diseases could affect lipid oxidation (JoumardCubizolles et al., 2017). $F_{2}$-isoprostanes derived from arachidonic acid are the most studied in diseases such as diabetes, cardiovascular, and neurodegenerative diseases (Milne et al., 2015). In a recent systematic review, the associations of 50 human conditions including obesity, metabolic syndrome, and type 1 and 2 diabetes as well as cardiovascular diseases and $\mathrm{F}_{2}$-isoprostanes were studied (van 't Erve et al., 2017). In the review, the authors quantified the associations and ranked the conditions with the conclusion that metabolic syndrome, type 2 diabetes, cardiovascular diseases, and smoking were associated with a relatively small increase in 8-iso-prostaglandin $\mathrm{F}_{2 \alpha}$ (also known as $15-\mathrm{F}_{2 \mathrm{t}}$-isoprostane), while conditions affecting kidney caused greater oxidative damage. In addition, medications can affect the levels of isoprostanes, with statins decreasing oxidative stress markers (Moutzouri et al., 2013).

Eicosapentaenoic acid (EPA) and docosahexaenoic acid (DHA) of the n-3 PUFA generate $F_{3}$-isoprostanes and $\mathrm{F}_{4}$-neuroprostanes, respectively, in nonenzymatic oxidation (Gao et al., 2006; Roberts et al., 1998). While $\mathrm{F}_{2^{-}}$ isoprostanes are thought to be disadvantageous to health, the possible physiological effects of $\mathrm{F}_{3}$-isoprostanes and $\mathrm{F}_{4}$-neuroprostanes are not yet confirmed, even though $\mathrm{F}_{4}$ neuroprostanes are suggested to reduce risk of atherosclerosis (Gladine et al., 2014), prevent ischemic injury in the heart (Roy et al., 2017), and be anti-arrhythmic (Roy et al., 2015). Nonenzymatic DHA peroxidation can result in numerous compounds out of which the isomer $4(R S)-4-\mathrm{F}_{4 \mathrm{t}^{-}}$ neuroprostane is the most abundant (Roberts et al., 1998; Roy et al., 2015). While little is known about the in vivo effect of alpha-linolenic acid (ALA) on oxidative stress, the oxidized product released namely phytoprostanes showed a promising protective effect in injured human neuronal cells (Minghetti et al., 2014).

Changes in dietary fat quality are hypothesized to alter the metabolized oxidized products and isoprostanes (Da Silva et al., 2017; Galano et al., 2015; Milne et al., 2015). PUFA are substrates for isoprostane formation and they can modify the fatty acid composition of tissues. As reviewed by Da Silva and coworkers (Da Silva et al., 2017), studies that have tested the effect of fish oil supplements have been able to show lower $\mathrm{F}_{2}$-isoprostanes. It is of note that the doses of EPA + DHA given to subjects were high (3-5 g/day) and lower doses did not result in significant changes in isoprostanes (Da Silva et al., 2017). Similarly, daily intake of EPA and DHA $(1 \mathrm{~g})$ from fish pate, fish oil, or fruit juice did not affect urinary $\mathrm{F}_{2}$ isoprostanes (Kirkhus et al., 2012). However, Hansson and coworkers (Hansson et al., 2015) suggested that the effects of fish on isoprostanes could be due to other bioactive compounds than fatty acids, but this has not been studied in interventions. The effect of flaxseed oil rich in ALA on oxidative stress has been tested in only one clinical trial reporting no effect on $\mathrm{F}_{2}$-isoprostanes, but it increased plasma and urine $F_{1}$-phytoprostanes (Barden et al., 2009). Olive oil rich in oleic acid has been reported to decrease $\mathrm{F}_{2}$-isoprostanes (Cicero et al., 2008) and replacing carbohydrate-containing foods with lean red meat for 8 weeks decreased urinary, but not plasma $\mathrm{F}_{2}$-isoprostanes compared to the group who continued their habitual diet (Hodgson et al., 2007). Nevertheless, these controlled nutritional interventions measuring appropriate types of isoprostanes (Galano et al., 2015) with sensitive and accurate mass spectrometry (MS) methods are limited and drawing conclusions based on these results is further hampered by differences between the studies related to their length and subjects' characteristics (Galano et al., 2015).

The aim of the study was to examine if fatty fish, lean fish, and Camelina sativa oil (CSO) affect urinary prostanoids in subjects with impaired glucose metabolism who participated in a randomized controlled study lasting for 12 weeks. CSO was chosen as it has a high content of ALA and relatively low content of phenolic compounds (Abramovič et al., 2007) and fatty fish as a source of EPA and DHA. We hypothesized that these $n-3$ fatty acids would affect urinary prostanoids. Furthermore, we hypothesized that because subjects with impaired glucose metabolism have increased oxidative stress (Odegaard et al., 2016; Seet et al., 2011), this could make them more prone to changes in oxidation after dietary modification.

\section{Subjects and Methods}

\section{Subjects}

Recruitment and characteristics of the subjects have previously been described (Schwab et al., 2018). The main inclusion criterion was fasting plasma glucose concentration $5.6-7.0 \mathrm{mmoL} / \mathrm{L}$. The 2 -h glucose concentration in the oral glucose tolerance test had to be $\leq 11.0 \mathrm{mmoL} / \mathrm{L}$. Other criteria 
for inclusion were: body mass index (BMI) $25-36 \mathrm{~kg} / \mathrm{m}^{2}$, age 40-75 years, concentrations of fasting serum total cholesterol $\leq 7 \mathrm{mmoL} / \mathrm{L}$, low-density lipoprotein (LDL) cholesterol $\leq 5.0 \mathrm{mmoL} / \mathrm{L}$, and total triacylglycerols $\leq 4.0 \mathrm{mmoL} / \mathrm{L}$. The main exclusion criteria included any chronic disease, a condition hampering the ability to follow the dietary intervention protocol, alcohol abuse ( $>40 \mathrm{~g} /$ day), weight loss of $\geq 5 \%$ during the preceding 6 months, and fish allergy. Altogether 153 Caucasian subjects were screened of which 96 fulfilled the inclusion criteria. Prior to the randomization for the study, eight subjects dropped out leaving 88 subjects to be randomized. Altogether 79 subjects completed the intervention and the measurement of urinary prostanoids was available from 72 subjects. The power calculation was based on differences in DHA in serum phospholipids, a valid biomarker of dietary intake (Serra-Majem et al., 2012) ( $n=18$ per group, difference of $1.2 \mathrm{~mol} \%$, when alpha $<0.05$ and beta $>0.9)$. The study plan has been approved by the Ethical committee of the Hospital District of Northern Savo, Finland. The subjects gave informed consent for participation in the study. The study is registered in Clinicaltrials.gov (NCT01768429).

\section{Study Design}

During the 4-week run-in period, the subjects followed their conventional diet and restrained from intake of any oil supplements or products enriched in plant stanols or sterols. After the run-in period, the subjects were randomly assigned into one of the four groups: CSO, fatty fish, lean fish, or control for 12 weeks. Randomization was stratified by sex and the use of statins. The major visits were at the beginning ( 0 week) and at the end of the study (12 weeks). Physical activity, alcohol intake, smoking, and use of medication known to affect the parameters measured were to be kept constant during the study.

\section{Study Diets}

The study diets were isocaloric and they were based on current nutrient recommendations (Becker et al., 2004; Perk et al., 2012) excluding fish and ALA intakes. Details of study diets have been reported (Schwab et al., 2018). The fatty fish group consumed four fish meals of fatty fish (e.g. salmon, rainbow trout) per week to provide $1 \mathrm{~g}$ of $\mathrm{n}-3$ PUFA composed of EPA and DHA per day. The lean fish group consumed four fish meals of lean fish (e.g. saithe, cod, pike, perch, and pike perch) per week. Subjects selfshopped for the fish and were instructed about the type of fish and food preparation methods. The dose of CSO was $30 \mathrm{~mL}$ per day to get $10 \mathrm{~g}$ ALA per day. CSO was provided in large containers and the subjects used a measuring cup for the daily portion intake. Also, CSO was allowed to be used as salad dressing or added unheated to food. The doses of CSO and fish were chosen to affect the primary endpoints (lipid and glucose metabolism) (Schwab et al., 2018). The fatty acid composition of CSO is presented in Table 1. The control and CSO groups were allowed to eat one fish meal per week and consumed mainly lean meat and chicken. The CSO group was given canola oil for food preparation and other groups received olive oil.

\section{Methods}

The body weight and height of the subjects were measured and used to calculate BMI $\left(\mathrm{kg} / \mathrm{m}^{2}\right)$. Questionnaire on smoking, medications, and supplements was completed by the subjects at 0 and 12 weeks.

The subjects kept 4-day food records (consecutive predefined days including one weekend day and checked by a clinical nutritionist at return) prior to the intervention and at 3,7 , and 11 weeks during the intervention to document the food intake. The food records were analyzed by AivoDiet nutrient calculation software (v. 2.0.2.1, Aivo Finland, Turku, Finland) based on national and international analyses, and international food composition tables. In addition to food records, compliance to diets was monitored by daily consumption records of fish and CSO.

Blood samples were drawn after a 10-h overnight fasting from an antecubital vein. Concentrations of serum total, LDL and high-density lipoprotein (HDL) cholesterol, and serum triacylglycerols were analyzed using commercial kits (981,813, 981,656, 981,823, and 981,786, respectively,

Table 1 Fatty acid composition of the Camelina sativa oil

\begin{tabular}{lll}
\hline Fatty acid & & mol\% \\
\hline $14: 0$ & Myristic acid & 0.1 \\
$16: 0$ & Palmitic acid & 5.7 \\
$18: 0$ & Stearic acid & 2.5 \\
$20: 0$ & Arachidic acid & 1.5 \\
$22: 0$ & Behenic acid & 0.3 \\
$24: 0$ & Lignoceric acid & 0.1 \\
Saturated fatty acids & & $\mathbf{1 0 . 2}$ \\
16:1n-7 & Palmitoleic acid & 0.1 \\
18:1n-9 & Oleic acid & 13.2 \\
$18: 1 \mathrm{n}-7$ & Cis-Vaccenic acid & 0.7 \\
20:1n-9+11 & Eicosenoic acid & 14.7 \\
$22: 1 \mathrm{n}-9$ & Erucic acid & 3.4 \\
$24: 1 \mathrm{n}-9$ & Nervonic acid & 0.6 \\
Monounsaturated fatty acids & & $\mathbf{3 2 . 7}$ \\
18:2n-6 & Linoleic acid & 16.4 \\
18:3n-3 & Alpha-linolenic acid & 38.4 \\
$20: 2 \mathrm{n}-6$ & Eicosadienoic acid & 22 \\
Polyunsturated & & $\mathbf{5 7 . 1}$
\end{tabular}

Polyunsaturated fatty acids 
Thermo Electron Corporation, Vantaa, Finland) and a Thermo Fisher Konelab 20XTi Analyzer (Thermo Electron Corporation, Vantaa, Finland). As an objective measure of dietary compliance, plasma fatty acids in phospholipids were measured by gas chromatography with 19:0 as the internal standard (Agren et al., 1992). The fatty acid composition of CSO was also measured by gas chromatography.

Urine was collected overnight for $12 \mathrm{~h}$ at both weeks 0 and 12. The subjects brought the urine to the clinic the following morning and aliquots of the urine were frozen in $-80{ }^{\circ} \mathrm{C}$. Creatinine levels were determined with enzymatic photometric test using creatinine reagent and measured using a Thermo Fisher Konelab 20XTi Analyzer (Thermo Electron Corporation, Vantaa, Finland).

\section{Preparation and Measurement of Urinary Prostanoids}

All organic solvents were at least analytical grade. Isoprostane standards were purchased from Cayman Chemical Co. (Ann Arbor, MI, USA) and 2,3,4,5-tetranor15- $\mathrm{F}_{2 \mathrm{t}}$-isoprostanes, $8-\mathrm{F}_{3 \mathrm{t}}$-isoprostanes, neuroprostanes, and neurofurans were synthesized at Institut des Biomolécules Max Mousseron (IBMM, Montpellier, France) as previously described (Guy et al., 2014; Oger et al., 2010).

The urine samples were prepared and quantified using the liquid chromatography-tandem mass spectrometry (LCMS/MS) method as previously described with modification (Lee and Lee, 2018). Briefly, the urine samples were thawed on ice and centrifuged at $11,000 \times \mathrm{g}$ for $3 \mathrm{~min}$ at $25{ }^{\circ} \mathrm{C}$ to remove the debris. A volume of $1 \mathrm{~mL}$ supernatant was acidified with $9 \mathrm{~mL}$ phosphoric acid buffer water $\left(\mathrm{H}_{2} \mathrm{PO}_{4}: \mathrm{H}_{2} \mathrm{O}\right.$, 4:96, v/v). Mixed anionic solid phase extraction (SPE, MAX, Waters, Milford, MA) was performed to extract the prostanoids. The eluent was dried under a stream of nitrogen at $37{ }^{\circ} \mathrm{C}$, then resuspended with internal standards $(0.1 \mathrm{ng} / \mu \mathrm{L})$ in methanol and immediately stored at $-20^{\circ} \mathrm{C}$ before analysis.

LC-MS/MS system consisting of a 1290 Infinity LC system (Agilent, Santa Clara, CA) with a $\mathrm{C}_{18}$ column $(2.6 \mu \mathrm{m}$ particle size, $150 \times 2.1 \mathrm{~mm}$, Phenomenex, Torrance, CA) maintained at $30{ }^{\circ} \mathrm{C}$ was used. The mobile phase consisted of $0.1 \%$ formic acid in water (A) and $0.1 \%$ formic acid in acetonitrile (B). The flow rate was set to $300 \mu \mathrm{L} / \mathrm{min}$ and the injection volume was $10 \mu \mathrm{L}$. The gradient was first maintained at $20 \%$ B for 2 min, then a linear gradient from $20 \%$ B to $98 \%$ B for 8 min, after which $98 \%$ B was held for 5 min. Finally, the column was reconditioned for the next run by return and maintaining at $20 \%$ B for $5 \mathrm{~min}$.

A QTrap 3200 triple quadrupole mass spectrometer (Sciex Applied Biosystems, Framingham, MA) coupled to the LC was operated in the negative electrospray ionization (ESI) mode. The spray voltage was set to $-4000 \mathrm{~V}$, and nitrogen gas was used as a curtain gas. The scan mode was multiple reaction monitoring (MRM). Quantitation of each analyte was determined by relating the peak area to its corresponding deuterated internal standard peak. For the analytes without their corresponding deuterated internal standards, quantitation was performed by using the replacement deuterated internal standards with similar structures and physical properties. 2,3-dinor-15- $\mathrm{F}_{2 \mathrm{t}}$-isoprostane, 2,3-dinor5,6-dihydro-15- $\mathrm{F}_{2 \mathrm{t}}$-isoprostane, 2,3,4,5-tetranor-15- $\mathrm{F}_{2 \mathrm{t}^{-}}$ isoprostane, $12-\mathrm{F}_{2 \mathrm{t}}$-isoprostane, and isofurans derived from arachidonic acid were quantified with $15-\mathrm{F}_{2 \mathrm{t}}$-isoprostane- $\mathrm{d}_{4}$, and $8-\mathrm{F}_{3 \mathrm{t}}$-isoprostane derived from EPA was quantified with EPA- $\mathrm{d}_{5}$. The mass ion $(\mathrm{m} / \mathrm{z})$ in this study was extracted from the standards available commercially and by IBMM and the others from LIPID MAPS database and literature reports. The intra-assay and interassay coefficients of variations ranged $12.68-20.21 \%$ and $13.42-26.89 \%$, respectively, and the lower level of detection for all the analytes was $<0.10 \mathrm{ng}$ (range 0.080-0.095 ng) with the matrix effect. The concentrations of the prostanoids were normalized with creatinine concentration to adjust for variations in the urinary flow rate.

\section{Statistical Analyses}

SPSS statistical software (v. 21, IBM Corp., Armonk, NY, USA) was used for statistical analyses. The data are reported as mean \pm SD unless otherwise indicated. Skewed distributions were normalized using logarithmic values. Repeated measures general linear model was used to test changes in dietary intake of nutrients. Fold changes were calculated dividing the end point values (12 weeks) with the values at baseline ( 0 week). Fold changes of fatty acids among the intervention groups were compared using analysis of covariance (ANCOVA) adjusted for age, gender, baseline value, and Bonferroni corrected post hoc tests. Similarly, for prostanoids, ANCOVA tests adjusted for baseline were performed. Within group changes (0 week vs 12 weeks) were analyzed using paired samples $t$-test or Wilcoxon signed ranks test. Due to multiple comparisons, the BenjaminiHochberg false discovery rate (FDR) was calculated for fatty acids using $\mathrm{R}$ Project for Statistical Computing, version 3.2.2. Spearman rank correlation coefficients were calculated between phospholipid fatty acids and isoprostanes. $p<0.05$ was considered as statistically significant.

\section{Results}

The baseline characteristics of the subjects are presented in Table 2 and dietary intake of nutrients is presented in Table 3. The number of smokers was 2, 3, 0, and 1 in the CSO, fatty fish, lean fish, and control groups, respectively. Similarly, the number of statin users was 3, 5, 4, and 4 . The mean number of fish meals per week was $4.4 \pm 0.4$, 
Table 2 Baseline characteristics of the subjects $(n=72)$

\begin{tabular}{ll}
\hline Characteristic & \\
\hline Age (years) & $58.9 \pm 6.5$ \\
Sex, female/male $(n)$ & $35 / 37$ \\
BMI $\left(\mathrm{kg} / \mathrm{m}^{2}\right)$ & $29.3 \pm 2.5$ \\
Serum cholesterol (mmol/L) & \\
$\quad$ Total & $5.3 \pm 1.0$ \\
LDL & $3.2 \pm 0.9$ \\
HDL & $1.4 \pm 0.4$ \\
Serum triacylglycerols (mmol/L) & $1.5 \pm 0.6$ \\
Use of statins $(n)$ & 16 \\
Smokers $(n)$ & 6 \\
Use of multivitamin or vitamin C supplements $(n)$ & 18 \\
Use of vitamin E supplement $(n)$ & 0 \\
Use of vitamin C supplement $(n)$ & 4 \\
\hline
\end{tabular}

Data are means $\pm \mathrm{SD}$ or frequencies $(n)$.

$4.3 \pm 0.5,0.9 \pm 0.4$, and $0.9 \pm 0.4$ in the fatty fish, lean fish, CSO, and control groups, respectively. The mean intake of CSO was $25.7 \pm 2.7 \mathrm{~g} /$ day in the CSO group. The intake of fat was higher in the CSO group $(42.5 \pm 3.6 \%$ of energy) than in the lean fish $(34.5 \pm 3.3 \%$ of energy) or the control group ( $34.3 \pm 5.3 \%$ of energy) and the fatty fish group (39.0 $\pm 5.1 \%$ of energy) had higher total fat intake than the control group (overall difference among the groups $p=0.001)$. ALA intake was higher in the CSO group ( $12.4 \pm 1.4 \mathrm{~g} /$ day) than in the other groups. EPA and DHA intakes in the fatty fish group $(501 \pm 227$ and $1150 \pm 650 \mathrm{mg} /$ day, respectively) were higher than in the control group $(85 \pm 81$ and $247 \pm 235 \mathrm{mg} /$ day, respectively). EPA intake in the lean fish group $(89 \pm 141 \mathrm{mg}$ /day) was lower than in the fatty fish group. Changes in dietary ALA, EPA, and DHA intake were reflected in the fatty acid composition of plasma phospholipids (Table 4). There was also a decrease in the proportion of arachidonic acid in the fatty fish group.

The urinary prostanoid levels at 0 and 12 weeks are presented in Table 5. There were only slight differences among the groups, where the only significant difference among the groups was prostaglandin $\mathrm{F}_{2 \alpha}\left(\mathrm{PGF}_{2 \alpha}\right)$ levels that were higher in the CSO group than in the control group $(p<0.05)$. The concentration of 2,3-dinor-5,6-dihydro$15-\mathrm{F}_{2 \mathrm{t}}$-isoprostane decreased in the CSO group $(p<0.05)$, however, there was no overall significance among the groups. Neurofurans were not detected in the urine. As statin use might affect isoprostanes levels and serum longchain n-3 PUFA levels (Bird et al., 2018), the analyses were rerun excluding the users of statins leaving 13 subjects in the CSO, 12 in the fatty fish, 17 in the lean fish, and 14 in the control group. There were no significant differences among the groups when statin users were excluded and the within group changes observed with all participants remained. Similarly, we tested the differences among the groups after excluding smokers and the results did not change (data not shown).

Total isoprostanes (sum of 5- $\mathrm{F}_{2 \mathrm{t}}$-isoprostane, 2,3-dinor15- $\mathrm{F}_{2 \mathrm{t}}$-isoprostane, 2,3-dinor-5,6-dihydro-15- $\mathrm{F}_{2 \mathrm{t}}$-isoprostanes, and 2,3,4,5-tetranor-15- $\mathrm{F}_{2 \mathrm{t}}$-isoprostanes) and 2,3,4,5-tetranor- $15-\mathrm{F}_{2 \mathrm{t}}$-isoprostanes correlated positively with arachidonic acid $(r=0.247$ and $r=0.237$, respectively) and negatively with ALA $(r=-0.326$ and $r=-0.319$, respectively) in phospholipids at 0 week (Table 6). Most of the correlations were weaker after the dietary intervention at 12 weeks and the fold changes of phospholipid fatty acids did not significantly correlate with the fold changes of isoprostanes. EPA in phospholipids did not significantly correlate with urinary $8-\mathrm{F}_{3 \mathrm{t}^{-}}$ isoprostane ( $r=-0.108$ at 0 week, $r=-0.019$ at 12 weeks, and $r=-0.065$ for fold changes) and similarly DHA did not correlate with $4(R S)-4-\mathrm{F}_{4 \mathrm{t}}$-neuroprostane $(r=0.011$ at 0 week, $r=-0.031$ at 12 weeks, and $r=-0.084$ for fold changes).

\section{Discussion}

We aimed to test the effect of CSO, fatty fish, and lean fish on urinary prostanoids in subjects with impaired glucose metabolism. There were no major changes after the 12-week diet periods. At baseline, ALA in plasma phospholipids was inversely associated with total isoprostanes, while arachidonic acid was positively associated.

The mean intake of CSO was $25.7 \mathrm{~g} /$ day, which provided $9.9 \mathrm{~g}$ ALA daily. CSO has relatively low content of phenolic compounds as compared to canola or olive oil (Abramovič et al., 2007), so the possible effects would have been expected to be contributed by the fatty acid composition. One earlier study investigated the effect of increased ALA intake (5.4 g/day) from flaxseed oil (Barden et al., 2009). Similarly, as in our study, there was no change in urinary total $\mathrm{F}_{2}$-isoprostanes. However, they observed an increase in $\mathrm{F}_{1}$-phytoprostanes (Barden et al., 2009), which originate from ALA. Furthermore, ALA in phospholipids correlated significantly with plasma $\mathrm{F}_{1^{-}}$ phytoprostanes (Barden et al., 2009). As we were not able to measure $F_{1}$-phytoprostanes, we could not assess all the oxidation markers that might have been affected by the ALA intake and further studies are needed to test the effect of ALA intake on $\mathrm{F}_{1}$-phytoprostanes.

Even though there was no significant overall effect on total $\mathrm{F}_{2}$-isoprostanes, one metabolite, 2,3-dinor5,6-dihydro- $15-\mathrm{F}_{2 \mathrm{t}}$-isoprostane, decreased in the CSO group. This metabolite has been suggested to be a more 


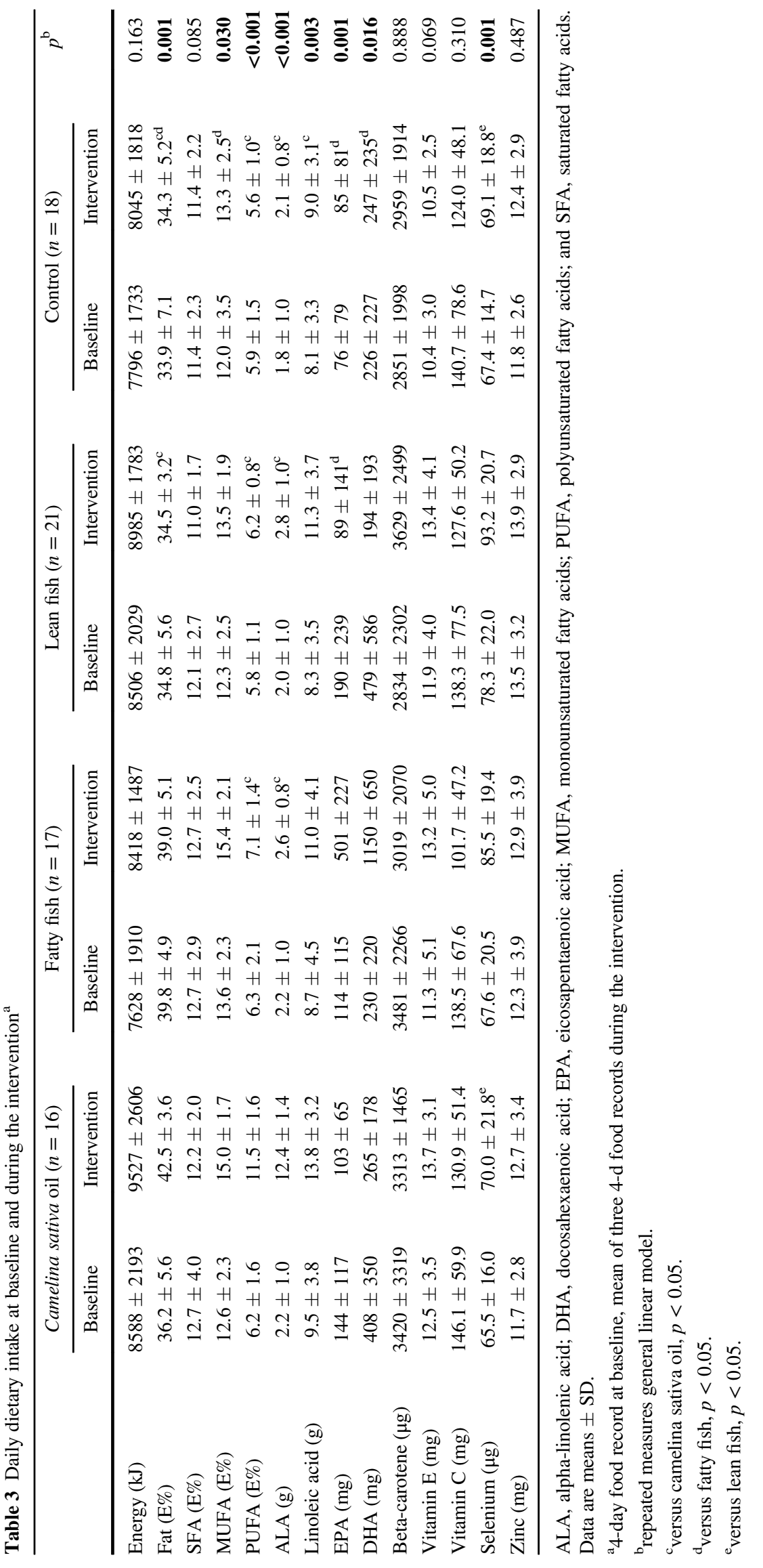




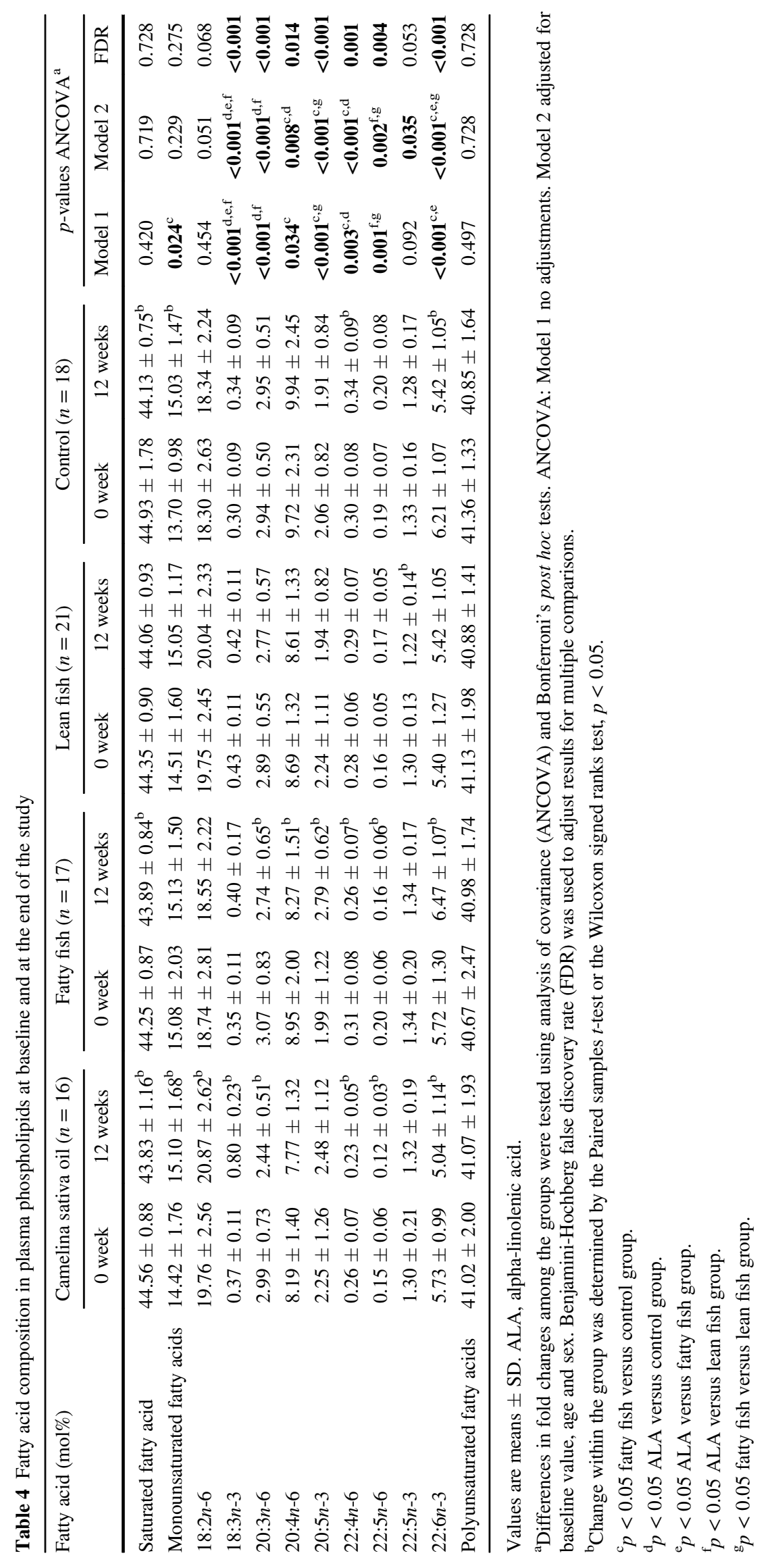




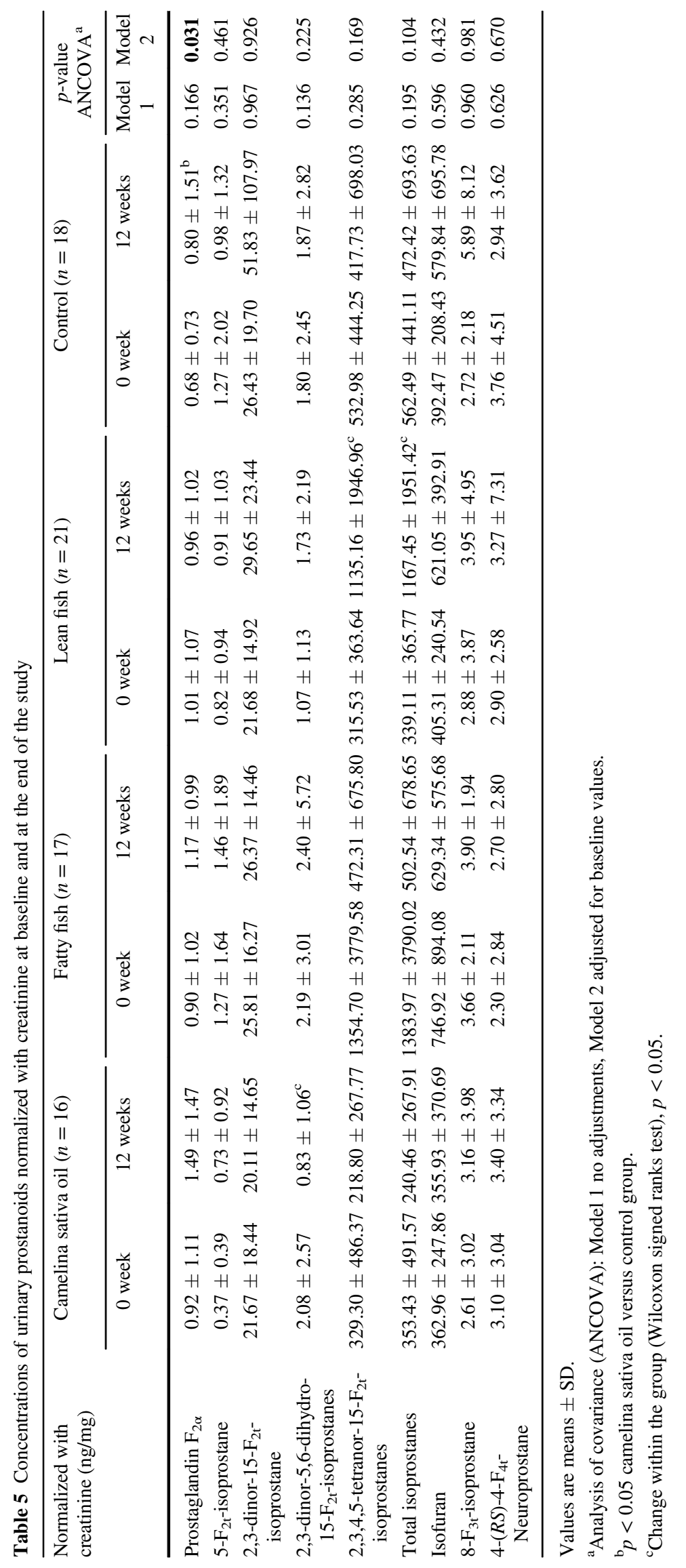


sensitive marker of oxidative stress in relation to antioxidant intake in an observational setting (Dorjgochoo et al., 2012). $\mathrm{PGF}_{2 \alpha}$ increased after the CSO diet as compared to the control diet. This is a surprising finding, as $\mathrm{PGF}_{2 \alpha}$ is an enzymatic oxidation product of arachidonic acid, and the proportion of arachidonic acid in plasma phospholipids did not significantly change in the CSO group. At baseline, we observed a significant negative correlation between plasma phospholipid ALA and total isoprostanes as well as a significant positive correlation between arachidonic acid and total isoprostanes. This could indicate that the habitual dietary fat quality as measured by biomarkers could relate to oxidative stress.

There are very little data on the effect of fatty fish consumption on isoprostanes and none on lean fish. One earlier intervention study tested the effect of fish pate $(1 \mathrm{~g} / \mathrm{day}$ $\mathrm{EPA}+\mathrm{DHA}$ ) and observed no effect on urinary $\mathrm{F}_{2^{-}}$ isoprostanes (Kirkhus et al., 2012), which supports our findings. In an observational study, higher total n-3 PUFA in erythrocytes were associated with a lower ratio of plasma $\mathrm{F}_{2}$-isoprostanes to $\mathrm{F}_{3}$-isoprostanes in Inuits (Alkazemi et al., 2016). An inverse association between 8 -iso-PGF ${ }_{2 \alpha}$ and habitual fatty fish intake was observed in young women (Hansson et al., 2015). As the association with fish consumption seemed to be stronger than that with serum phospholipid EPA and DHA, the group suggested that other bioactive compounds like taurine or anserine could contribute to the lower 8-iso-PGF $2 \alpha$. However, our results in the lean fish group do not support this. Based on several interventions that tested the effect of fish oils on $\mathrm{F}_{2^{-}}$ isoprostanes, it is suggested that the dose needs to be high (3-5 g/day) to cause significant changes (Da Silva et al., 2017). Such high doses are impractical to get from dietary sources (mean daily intake of EPA was $0.5 \mathrm{~g}$ and DHA $1.2 \mathrm{~g}$ in this study in the fatty fish group). Thus, current evidence does not support that long-chain $n-3$ fatty acids in the range that can be derived from food or fish consumption would have a major impact on the prostanoids.

The advantage of this study is the measurement of $\mathrm{F}_{3^{-}}$ isoprostanes and $\mathrm{F}_{4}$-neuroprostanes, derived from EPA and DHA, respectively. However, we did not observe changes in these in the fatty fish group or correlations between them. One previous study reported nondetectable plasma levels of $\mathrm{F}_{3}$-isoprostanes and $\mathrm{F}_{4}$-neuroprostanes after EPA and DHA supplementation (Mas et al., 2010). The metabolism and excretion of $\mathrm{F}_{3}$-isoprostanes and $\mathrm{F}_{4}$ neuroprostanes are still poorly known (Galano et al., 2017) and we cannot explain the lack of effect in our study. Formerly, $\mathrm{F}_{4}$-neuroprostanes were noted as a biomarker of oxidative stress in neurodegeneration (Galano et al., 2017), but in more recent studies $\mathrm{F}_{3}$-isoprostanes and $\mathrm{F}_{4}$ neuroprostanes are suggested to have cardioprotective roles (Roy et al., 2016, 2017). 
Results on the effects of different fatty acids or their food sources on urinary isoprostanes are still inconclusive. Differences in subjects' characteristics (health conditions), samples (blood/urine), measured outcomes (isoprostanes), duration of studies, and analysis methods could have contributed to the discrepancies. Nonetheless, it is hypothesized that under chronic oxidative stress or prolonged disease state, both urinary and plasma isoprostanes would be elevated (Halliwell and Lee, 2010). Isoprostanes and their metabolites are a large group of compounds originating from different fatty acids, and different compounds have been reported in different interventions (Galano et al., 2015). Due to mixed results, there is no agreement on preferable outcomes or samples that should be used in dietary interventions (Galano et al., 2015). GC-MS is regarded as a well validated method for isoprostane measurement, however, many dietary studies have used immunoassays that can detect only selected isoprostanes and may overestimate amounts due to cross-reactivity (Galano et al., 2015; Vigor et al., 2014). More so, most of the isoprostanes derived from EPA and DHA are not commercially available. Further studies are needed to investigate what are the ideal markers of oxidative stress in dietary studies and what are their roles in the disease process.

There are several limitations in this study. The sample size might have been too small to detect possible differences. It is of note that there were large individual variations in the level of some isoprostanes (e.g. 2,3,4,5-tetranor-15- $\mathrm{F}_{2 \mathrm{t}}$-isoprostanes) and this was also identified in urine of healthy males after isocaloric high or low protein diets (Mok et al., 2016), and both studies used the same LC-MS/MS analysis. It is anticipated that the method of measurement was not the limiting factor because large individual variations of isoprostanes levels in urine of healthy subjects with metabolic syndrome (Seet et al., 2010) and subjects with type 2 diabetes (Seet et al., 2011) measured by GC-MS were shown. The urinary isoprostanes could have been modified by lifestyle factors, use of medications, and dietary factors that we could not control. Some of our study subjects smoked and used statins, however, they were instructed not to change their lifestyle habits or medications during the study. We had data on dietary and supplemental intake on antioxidants, but no biomarker data reflecting intake of antioxidants or phenolic compounds. It is also of note that the fatty fish, lean fish, and control groups used olive oil in food preparation and the effect of olive oil on urinary isoprostanes has been inconclusive (Cicero et al., 2008; Visioli et al., 2005). Fish is a source of environmental contaminants such as mercury and polychlorinated biphenyls (PCB) and it has been proposed that these could increase oxidative stress (Alkazemi et al., 2016). We did not have data for these contaminants.
Strength of this study is that we reported data for multiple isoprostanes including isofurans, neurofurans, $\mathrm{F}_{3-}$ isoprostanes, and $\mathrm{F}_{4}$-neuroprostanes measured with $\mathrm{LC}$ MS/MS. Subjects had impaired glucose metabolism, which could have made them more prone to oxidative stress and increased the likelihood to observe changes in these markers. Data are from randomized clinical trial testing commonly used food items. Compliance to the study diets was good and it was monitored both with self-reporting dietary intake and using valid biomarkers of dietary fat quality. Our study was relatively long as the duration of many earlier studies has been 4-8 weeks (Da Silva et al., 2017).

In conclusion, $\mathrm{CSO}$, fatty fish, and lean fish consumption do not cause major changes in oxidative stress markers in subjects with impaired glucose metabolism.

Acknowledgements The authors thank Tuomas Onnukka, Erja Kinnunen, and Päivi Turunen for excellent technical assistance. Suomen Kasviöljyt Ltd., Kesko Ltd., and Bunge Finland Ltd. provided oil and fat spreads. This study was financially supported by Finnish Diabetes Research Foundation; Competitive Research Funding of the Northern Savo Hospital District special state subsidy for health research; Juho Vainio Foundation; the Central Foundation and the North Savo Regional Fund of the Finnish Cultural Foundation; Paavo Nurmi Foundation; and Yrjö Jahnsson Foundation (grant number 6437).

Conflict of Interest The authors declare that they have no conflict of interest.

\section{References}

Abramovič, H., Butinar, B., \& Nikolič, V. (2007) Changes occurring in phenolic content, tocopherol composition and oxidative stability of Camelina sativa oil during storage. Food Chemistry, 104:903-909. https://doi.org/10.1016/j.foodchem.2006. 12.044

Ågren, J. J., Julkunen, A., \& Penttilä, I. (1992) Rapid separation of serum lipids for fatty acid analysis by a single aminopropyl column. Journal of Lipid Research, 33:1871-1876.

Alkazemi, D., Jackson 2nd, R. L., Chan, H. M., \& Kubow, S. (2016) Increased F3-Isoprostanes in the Canadian Inuit population could be cardioprotective by limiting F2-isoprostane production. The Journal of Clinical Endocrinology and Metabolism, 101: 3264-3271. https://doi.org/10.1210/jc.2015-4096

Barden, A. E., Croft, K. D., Durand, T., Guy, A., Mueller, M. J., \& Mori, T. A. (2009) Flaxseed oil supplementation increases plasma F-1-phytoprostanes in healthy men. Journal of Nutrition, 139: 1890-1895. https://doi.org/10.3945/jn.109.108316

Becker, W., Lyhne, N., Pedersen, A. N., Aro, A., Fogelholm, M., Phorsdottir, I., ... Pedersen, J. I. (2004) Nordic nutrition recommendations 2004-Integrating nutrition and physical activity. Scandinavian Journal of Nutrition, 48:178-187. https://doi.org/10.1080/ 1102680410003794

Bird, J., Calder, P., \& Eggersdorfer, M. (2018) The role of n-3 long chain polyunsaturated fatty acids in cardiovascular disease prevention, and interactions with statins. Nutrients, 10:775. https://doi.org/ 10.3390/nu10060775 
Cicero, A. F., Nascetti, S., Lopez-Sabater, M. C., Elosua, R., Salonen, J. T., Nyyssonen, K., ... EUROLIVE Study Group (2008) Changes in LDL fatty acid composition as a response to olive oil treatment are inversely related to lipid oxidative damage: The EUROLIVE study. Journal of the American College of Nutrition, 27:314-320.

Da Silva, M. S., Bilodeau, J. F., Julien, P., \& Rudkowska, I. (2017) Dietary fats and F2-isoprostanes: A review of the clinical evidence. Critical Reviews in Food Science and Nutrition, 18:3929-3941. https://doi.org/10.1080/10408398.2016.1196646

Dorjgochoo, T., Gao, Y. T., Chow, W. H., Shu, X. O., Yang, G., Cai, Q., ... Dai, Q. (2012) Major metabolite of F2-isoprostane in urine may be a more sensitive biomarker of oxidative stress than isoprostane itself. The American Journal of Clinical Nutrition, 96: 405-414. https://doi.org/10.3945/ajcn.112.034918

Galano, J. M., Lee, Y. Y., Durand, T., \& Lee, J. C. Y. (2015) Special issue on "Analytical methods for oxidized biomolecules and antioxidants" The use of isoprostanoids as biomarkers of oxidative damage, and their role in human dietary intervention studies. Free Radical Research, 49:583-598. https://doi.org/10.3109/10715762. 2015.1007969

Galano, J. M., Lee, Y. Y., Oger, C., Vigor, C., Vercauteren, J., Durand, T., ... Lee, J. C. (2017) Isoprostanes, neuroprostanes and phytoprostanes: An overview of 25years of research in chemistry and biology. Progress in Lipid Research, 68:83-108.

Gao, L., Yin, H., Milne, G. L., Porter, N. A., \& Morrow, J. D. (2006) Formation of F-ring Isoprostane-like compounds (F3-Isoprostanes) in vivo from eicosapentaenoic acid. Journal of Biological Chemistry, 281:14092-14099. https://doi.org/10.1074/jbc.M601035200

Gladine, C., Newman, J. W., Durand, T., Pedersen, T. L., Galano, J. M., Demougeot, C., ... Comte, B. (2014) Lipid profiling following intake of the omega 3 fatty acid DHA identifies the peroxidized metabolites F4-neuroprostanes as the best predictors of atherosclerosis prevention. PLoS One, 9:e89393. https://doi.org/10. 1371/journal.pone.0089393

Guy, A., Oger, C., Heppekausen, J., Signorini, C., De Felice, C., Furstner, A., ... Galano, J. M. (2014) Oxygenated metabolites of n3 polyunsaturated fatty acids as potential oxidative stress biomarkers: Total synthesis of 8-F3t-IsoP, 10-F4t-NeuroP and [D4]10-F4t-NeuroP. Chemistry, 20:6374-6380. https://doi.org/10.1002/ chem. 201400380

Halliwell, B., \& Lee, C. Y. (2010) Using isoprostanes as biomarkers of oxidative stress: Some rarely considered issues. Antioxidants \& Redox Signaling, 13:145-156. https://doi.org/10.1089/ars.2009. 2934

Hansson, P., Barregard, L., Halltorp, M., Sibthorpe, S., Svelander, C., Sandberg, A. S., ... Hulthen, L. (2015) Habitual high intake of fatty fish is related to lower levels of $\mathrm{F}(2)$-isoprostane in healthy women. Nutrition, 31:847-852. https://doi.org/10.1016/j.nut.2014.12.015

Hodgson, J. M., Ward, N. C., Burke, V., Beilin, L. J., \& Puddey, I. B. (2007) Increased lean red meat intake does not elevate markers of oxidative stress and inflammation in humans. The Journal of Nutrition, 137:363-367.

Joumard-Cubizolles, L., Lee, J. C., Vigor, C., Leung, H. H., BertrandMichel, J., Galano, J. M., ... Gladine, C. (2017) Insight into the contribution of isoprostanoids to the health effects of omega 3 PUFAs. Prostaglandins \& Other Lipid Mediators, 133:111-122.

Kirkhus, B., Lamglait, A., Eilertsen, K., Falch, E., Haider, T., Vik, H., ... Ulven, S. M. (2012) Effects of similar intakes of marine n-3 fatty acids from enriched food products and fish oil on cardiovascular risk markers in healthy human subjects. British Journal of Nutrition, 107:1339-1349. https://doi.org/10.1017/ S0007114511004508

Lee, Y. Y., \& Lee, J. C. (2018) LC-MS/MS analysis of lipid oxidation products in blood and tissue samples. Methods in Molecular Biology, 1730:83-92. https://doi.org/10.1007/978-1-4939-7592-1_6
Mas, E., Woodman, R. J., Burke, V., Puddey, I. B., Beilin, L. J., Durand, T., \& Mori, T. A. (2010) The omega-3 fatty acids EPA and DHA decrease plasma F(2)-isoprostanes: Results from two placebo-controlled interventions. Free Radical Research, 44: 983-990. https://doi.org/10.3109/10715762.2010.492830

Milne, G. L., Dai, Q., \& Roberts, L. J. (2015) The isoprostanes-25 years later. Biochimica et Biophysica Acta (BBA)-Molecular and Cell Biology of Lipids, 1851:433-445. https://doi.org/10.1016/j. bbalip.2014.10.007

Minghetti, L., Salvi, R., Lavinia Salvatori, M., Ajmone-Cat, M. A., De Nuccio, C., Visentin, S., ... Durand, T. (2014) Nonenzymatic oxygenated metabolites of alpha-linolenic acid B1- and L1-phytoprostanes protect immature neurons from oxidant injury and promote differentiation of oligodendrocyte progenitors through PPAR-gamma activation. Free Radical Biology \& Medicine, 73: 41-50. https://doi.org/10.1016/j.freeradbiomed.2014.04.025

Mok, A., Haldar, S., Lee, J. C., Leow, M. K., \& Henry, C. J. (2016) Postprandial changes in cardiometabolic disease risk in young Chinese men following isocaloric high or low protein diets, stratified by either high or low meal frequency-A randomized controlled crossover trial. Nutrition Journal, 15:27. https://doi.org/10.1186/ s12937-016-0141-5

Morrow, J. D., Hill, K. E., Burk, R. F., Nammour, T. M., Badr, K. F., \& Roberts 2nd, L. J. (1990) A series of prostaglandin F2-like compounds are produced in vivo in humans by a non-cyclooxygenase, free radical-catalyzed mechanism. Proceedings of the National Academy of Sciences of the United States of America, 87: 9383-9387.

Moutzouri, E., Liberopoulos, E. N., Tellis, C. C., Milionis, H. J., Tselepis, A. D., \& Elisaf, M. S. (2013) Comparison of the effect of simvastatin versus simvastatin/ezetimibe versus rosuvastatin on markers of inflammation and oxidative stress in subjects with hypercholesterolemia. Atherosclerosis, 231:8-14. https://doi.org/ 10.1016/j.atherosclerosis.2013.08.013

Odegaard, A. O., Jacobs, D. R., Sanchez, O. A., Goff, D. C., Reiner, A. P., \& Gross, M. D. (2016) Oxidative stress, inflammation, endothelial dysfunction and incidence of type 2 diabetes. Cardiovascular Diabetology, 15:51. https://doi.org/10.1186/ s12933-016-0369-6

Oger, C., Bultel-Ponce, V., Guy, A., Balas, L., Rossi, J. C., Durand, T., \& Galano, J. M. (2010) The handy use of Brown's P2-Ni catalyst for a skipped diyne deuteration: Application to the synthesis of a [D4]-labeled F4t-neuroprostane. Chemistry, 16: 13976-13980. https://doi.org/10.1002/chem.201002304

Perk, J., De Backer, G., Gohlke, H., Graham, I., Reiner, Z., Verschuren, M., ... European Association for Cardiovascular Prevention \& Rehabilitation (EACPR), \& ESC Committee for Practice Guidelines (CPG) (2012) European Guidelines on cardiovascular disease prevention in clinical practice (version 2012). The Fifth Joint Task Force of the European Society of Cardiology and Other Societies on Cardiovascular Disease Prevention in Clinical Practice (constituted by representatives of nine societies and by invited experts). European Heart Journal, 33:1635-1701.

Roberts, L. J., Montine, T. J., Markesbery, W. R., Tapper, A. R., Hardy, P., Chemtob, S., ... Morrow, J. D. (1998) Formation of Isoprostane-like compounds (neuroprostanes) in vivo from docosahexaenoic acid. Journal of Biological Chemistry, 273: 13605-13612. https://doi.org/10.1074/jbc.273.22.13605

Roy, J., Fauconnier, J., Oger, C., Farah, C., Angebault-Prouteau, C., Thireau, J., ... Le Guennec, J. Y. (2017) Non-enzymatic oxidized metabolite of DHA, 4(RS)-4-F4t-neuroprostane protects the heart against reperfusion injury. Free Radical Biology \& Medicine, 102: 229-239.

Roy, J., Le Guennec, J., Galano, J., Thireau, J., Bultel-Poncé, V., Demion, M., ... Durand, T. (2016) Non-enzymatic cyclic oxygenated metabolites of omega-3 polyunsaturated fatty acid: Bioactive 
drugs? Biochimie, 120:56-61. https://doi.org/10.1016/j.biochi. 2015.06.010

Roy, J., Oger, C., Thireau, J., Roussel, J., Mercier-Touzet, O., Faure, D., ... Le Guennec, J. Y. (2015) Nonenzymatic lipid mediators, neuroprostanes, exert the antiarrhythmic properties of docosahexaenoic acid. Free Radical Biology \& Medicine, 86:269-278. https://doi.org/10.1016/j.freeradbiomed.2015.04.014

Schwab, U. S., Lankinen, M. A., de Mello, V. D., Manninen, S. M., Kurl, S., Pulkki, K. J., ... Erkkilä, A. T. (2018) Camelina sativa oil, but not fatty fish or lean fish, improves serum lipid profile in subjects with impaired glucose metabolism-a randomized controlled trial. Molecular Nutrition \& Food Research, 62:1700503. https://doi.org/10.1002/mnfr.201700503

Seet, R. C., Lee, C. Y., Lim, E. C., Quek, A. M., Huang, H., Huang, S. H., ... Halliwell, B. (2011) Oral zinc supplementation does not improve oxidative stress or vascular function in patients with type 2 diabetes with normal zinc levels. Atherosclerosis, 219:231-239.

Seet, R. C., Lee, C. Y., Lim, E. C., Quek, A. M., Huang, S. H., Khoo, C. M., \& Halliwell, B. (2010) Markers of oxidative damage are not elevated in otherwise healthy individuals with the metabolic syndrome. Diabetes Care, 33:1140-1142. https://doi.org/10.2337/ dc09-2124

Serra-Majem, L., Nissensohn, M., Overby, N. C., \& Fekete, K. (2012) Dietary methods and biomarkers of omega 3 fatty acids: a systematic review. The British Journal of Nutrition, 107 Suppl 2: S64-S76. https://doi.org/10.1017/S000711451200147X

van 't Erve, T. J., Kadiiska, M. B., London, S. J., \& Mason, R. P. (2017) Classifying oxidative stress by F2-isoprostane levels across human diseases: A meta-analysis. Redox Biology, 12:582-599. https://doi.org/10.1016/j.redox.2017.03.024

Vigor, C., Bertrand-Michel, J., Pinot, E., Oger, C., Vercauteren, J., Le Faouder, P., ... Durand, T. (2014) Non-enzymatic lipid oxidation products in biological systems: assessment of the metabolites from polyunsaturated fatty acids. Journal of Chromatography.B, Analytical Technologies in the Biomedical and Life Sciences, 964:65-78. https://doi.org/10.1016/j.jchromb.2014.04.042

Visioli, F., Caruso, D., Grande, S., Bosisio, R., Villa, M., Galli, G., ... Galli, C. (2005) Virgin olive oil study (VOLOS): Vasoprotective potential of extra virgin olive oil in mildly dyslipidemic patients. European Journal of Nutrition, 44:121-127. https://doi.org/10. 1007/s00394-004-0504-0 